\title{
ENTREVISTA COM GUNTHER DIETZ ${ }^{1}$
}

DANIELLE ARAUJO ${ }^{2}$

UNILA

Gunther Dietz ${ }^{3}$ es doctor en Antropologia de América, Filosofía y Filología Hispanica en las Universidades de Gotinga y Hamburgo (Alemania), Magister Artium (M. A.) y doctor (Dr. phil.) en Antropología por la Universidad de Hamburgo (Alemania); docencia en las Universidades de Hamburgo, Granada (España), Aalborg (Dinamarca), Ghent (Bélgica), Veracruzana (México) y Deusto (España), Investigador Titular en el Instituto de Investigaciones en Educación de la Universidad Veracruzana (Xalapa, México) y miembro del Sistema Nacional de Investigadores, del Consejo Mexicano de Investigación Educativa, de la Academia Mexicana de Ciencias y de la International Association for Intercultural Education (IAIE).

Trabajos de campo etnográficos sobre artesanías e "indigenismo" así como sobre comunidades indígenas y movimientos étnicos en Michoacán (México) y sobre colectivos inmigrantes, organizaciones nogubernamentales, movimientos sociales, multiculturalismo y educación intercultural en Hamburgo (Alemania), en Andalucía (España) y en Veracruz (México). Actualmente dirige el proyecto de investigación "Diálogo de saberes, haceres y poderes entre actores educativos y comunitarios: una etnografía reflexiva de la educación superior intercultural en Veracruz" (InterSaberes), realizado por el Instituto de Investigaciones en Educación y la Universidad Veracruzana Intercultural y patrocinado por el Consejo Nacional de Ciencia y Tecnología (CONACyT, convocatoria Ciencia Básica).

\footnotetext{
${ }^{1}$ Entrevista realizada em outubro de 2015, no México. Transcrição de Renata Brasileiro.

${ }^{2}$ Antropóloga e docente da Universidade Federal da Integração Latino-americana (UNILA). E-mail: danielle.araujo@unila.edu.br

${ }^{3}$ E-mail: gdietz@uv.mx; guntherdietz@gmail.com. Web: www.uv.mx/iie/personal-academico/gunther/.
} 
Principales áreas de interés: interculturalidad, etnicidad y educación intercultural e inter-religiosa; movimientos étnicos $\mathrm{y} / \mathrm{o}$ regionalistas, pueblos indios y autonomías; organizaciones nogubernamentales como nuevos sujetos de desarrollo; multiculturalismo, diversidad cultural y religiosa, comunidades migrantes y sociedades de acogida.

Danielle: Bom dia, Gunther. Um prazer enorme poder conversar com você. Gostaria que você nos falasse das suas perspectivas sobre a interculturalidade.

Gunther: Obrigado, Danielle. Para mim é muito importante quando falamos de interculturadidade fazermos referências aos próprios autores; quais são suas reivindicações e como chegam a este discurso. Aos modelos de educação intercultural. Creio que é muito importante ter em conta que tanto no âmbito anglo-saxônico como no âmbito latinoamericano são os movimentos sociais que reivindicam outro tipo de educação. Uma educação mais pertinente, algo que tenha a ver com direitos coletivos. Nesse sentido, o multiculturalismo como um programa político é o ponto de partida para as propostas chamadas de interculturais. Em cada país, estas propostas têm se articulado de forma muito diferente. Por exemplo, aqui no México existe uma forte presença do Estado, porque o Estado-nação mexicano tem tido um papel protagonista no sistema educativo. Em outros países, como, por exemplo, no Chile, eu não sei exatamente no Brasil, mas em muitos países tem sido a cooperação internacional que tem se dedicado a difundir o discurso intercultural. Em outros países têm sido as instituições privadas - a educação privada, a educação internacional, de colégios internacionais etc, então, para mim é muito importante reconhecer quais são os grupos e as comunidades que reivindicam, segundo um determinado tipo de educação e como se inserta esse discurso no sistema educativo nacional.

Danielle: Como voçê observa essa relação com o Estado aqui no México? 
Gunther: No México, apesar de se falar muito de universidades interculturais, escolas interculturais, a ideia segue sendo a de um Estadonação que através de um currículo nacional único começa a diversificálo. Mas continua de o pensamento estar direcionado aos povos originários, e os migrantes continuam sem direito ao currículo diversificado. Isso contrasta muito com a situação na Europa, onde o discurso intercultural tem se convertido em quase sinônimo de atenção à diversidade em relação a migrações, e sobretudo migrações que lá chamam de migrações extracomunitárias. É muito chamativo que se está utilizando modelos educativos segregadores ou pluralizadores muito parecidos em um caso para povos indígenas, e em outro caso para comunidades migrantes. Os problemas educativos são completamente diferentes, então, por isso eu acredito que é muito importante construir um currículo intercultural de forma indutiva, levando em consideração o contexto e desde baixo ir construindo propostas educativas pertinentes. Propostas educativas culturalmente situadas, localmente arraigadas, então, para isso creio que existam muitas propostas para a inovação pedagógica que são compatíveis com o pensamento complexo de Morin. Alguns países da América Latina seguem copiando, queiram ou não, o modelo francês.

Danielle: Bom, você me diz que no caso do Mexico a educação vem de cima para baixo. Os governos fazem uma grande divulgação de escolas interculturais, sabemos o quanto as propostas são dificeis de serem concretizadas. Como é isso?

Gunther: Claro! Eu sempre digo que interculturalidade é um conceito esponja, não por adotar muitos conteúdos diferentes, mas no fundo não acaba significando nada. O Estado-nação mexicano, nas últimas duas décadas, tem gerado um conceito de interculturalidade que é quase um sinônimo de uma boa educação para povos indígenas, mas isso gera novas contradições. Primeiro porque vem desde cima e de forma homogeizante, então se entende a interculturalidade de forma homogénea, o que é uma contradição. Em segundo lugar porque a tarefa de interculturalizar as minorias não é o bastante quando todos sabemos 
que o problema principal das sociedades latino-americanas são as maiorias silenciosas. São os mestiços. É a classe média, são todos aqueles que não creem ter a necessidade de gestionar a diversidade, então, de uma alguma forma, se atribui aos povos ao invés de atribuir à sociedade. A sociedade maioritária precisa enfrentar as questões da diversidade e é por isso que é importante aprender de outros contextos onde têm existido uma educação antirracista. Uma educação empoderadora, uma educação inovadora que volte a questão central como parte do problema e não só se refere unicamente às vítimas. Nossas sociedades são excludentes, nossas sociedades são discriminatórias, mas se desenvolvermos modelos educativos só para as vítimas, então, seguimos marginalizando, enquanto que os que marginalizam seguem sendo monolíngues, monoculturais e em resumo aprendemos inglês; e em resumo aprendemos interculturalidade desde cima, pelos Estados Unidos, mas não nos enfrentamos com nosso próprio legado racista, colonialista que temos em relação aos povos originários, isso é um dos principais problemas, por isso eu sustento que necessitamos de modelos diversificados de educação. Os povos originários, que estão diante de uma memória colonial muito forte, requerem um tipo de educação muito indutiva, muito comunal, muito desde o local, mas os descendentes dos criollos, os mestiços, os que formam parte da sociedade integrada a que se acredita homogênea, a que se acredita monocultura, eles requerem um tipo de educação crítica problematizadora, desmistificadora dos grandes mitos da homogeneidade nacional etc., e isso é um tipo de educação diferente, não pode haver um modelo educativo intercultural em uma sociedade tão desigual como são as sociedades latino-americanas.

Danielle: Com certeza, sim, isso é certo, mas como desenvolver uma interculturalidade desde baixo? Tendo como princípio a questão do Estado-nação que de fato, no final das contas, é quem dá as cartas. Então como fazer essa interculturalidade desde baixo possibilitando que as comunidades se protagonizem?

Gunther: É uma situação muito paradoxal. Aqui, no México houve uma mudança política no ano 2000. Antes do ano 2000 governava o partido do Estado, o grande partido, aquele que homogeneizava a todos, os que 
prometiam sempre a integração para todos, mas agora desde do ano 2000 tem ocorrido uma situação muito paradoxal: os governos neoliberais, que no fundo só pensam na elite integrada e não nos excluídos, têm gerado determinadoas espaços, principalmente deixando que algumas propostas educativas que não os interessa possam lograr. Tem ocorrido o paradoxo de que os movimentos indígenas, os zapatistas, por exemplo, em Chiapas, os movimentos reivindicam autonomia e em troca concedem interculturalidade, no sentido que: façam vocês em nível comunal, em nível municipal seus próprios modelos educativos, nós vamos acreditar desde cima, mas não vamos nos meter nos detalhes. Então, existem certos espaços nos que se pode conseguir uma certa autonomia educativa em nível comunal, a nível regional, com certos espaços de reconhecimento, de modelos endogénos. Por exemplo, em Nuaca tem acontecido modelos muito interessantes, experiências muito boas com a chamada comunalidade. Como construir a partir da ideologia do comunalismo nosso, como comunidade, e a partir daí criar um currículo inclusivo desde baixo, isso agora tem sido reconhecido, por parte deste tipo de governo, e é algo completamente novo, algo que nunca havia ocorrido antes e eu acredito que se pode ir construindo desde baixo em certos contextos porque existem certos governos que outorgam certas margens de autonomía. Em outros casos houve boas experiências com governos mais progressistas que queriam seguir com esta ideia de que o Estado tem uma necessidade, tem a obrigação de outorgar direitos, mas se negocia em nível estadual. Em alguns estados mexicanos, como na Cidade do México, têm existido avanços com um currículo intercultural, porque governos de esquerda têm reconhecido as demandas dos atores sociais. Então, há certas margens de manobra para que indutivamente se possa ir reconhecendo estes espaços. Mas certamente que é um processo de apertar e soltar, é um processo que o Estado continuamente se retira, confunde as demandas dos povos originários com uma espécie de autosustentação de subcontratação, a autores privados, ou a ONGs, então é um campo muito conflitivo e por isso também que é preciso ensinar que todo esse debate da interculturalidade não tem sentido com a paz, a harmonia, a tolerância, senão com competências para impor-se em situações muito conflitivas e muito assimétricas. 
Danielle: Sim, bom, muchas gracias, Gunther, foi um prazer estar aqui com você.

Recebido em: 02/12/2015 * Aprovado em: 13/12/2015 * Publicado em: 31/12/2015 